Proceedings of the Institution of
Civil Engineers
Maritime Engineering 162
December 2009 Issue MA4
Pages $187-196$
doi: $10.1680 /$ maen.2009.162.4.187
Paper 900006
Received 25/02/2009
Accepted 06/03/2009
Keywords:
maritime engineering/renewable
energy /research \& development

\title{
Marine renewable energy development - research, design, install
}

D. Greaves BEng, DPhil(Oxon), CEng, MRINA, G. Smith BSc, PhD, CEng, MIP, MIMarEST, M. Attrill BSc, PhD, M. Belmont BSc, PhD, A. Chadwick MSc, PhD, CEng, MICE, D. Conley BSc, PhD, A. Eccleston BSc, PhD, CMet, FRMetS, MNI, FHEA, B. Godley BSc, BVMS, PhD, N. Harrington BSc, MRICS, C. L. Hor BEng, PhD, MIET, MIEEE, P. Hosegood MSc, PhD, L. Johanning Dipllng, PhD, D. Millar PhD, S. Pan MSc, PhD, D. Reeve BSc, PhD, FICE, FRMetS, FIMA, J. Williams BSc, PhD, J. Wolfram BSc, PhD, CEng, FRINA, J. Xu MSc, PhD, AFRIN, CNI, FHEA, A. Zobaa MSc, PhD, CEng, FIET, SMIEEE and Q. Zou BSc, PhD

The UK government has committed to a reduction of carbon dioxide emissions for England and Wales by $20 \%$ below 1990 levels by 2010 and to increase the amount of electrical energy generated by renewable energy sources to $10 \%$ by 2010 and $15 \%$ by 2015 . Wave and tidal energy are likely to contribute significantly to achieving these targets as important renewable energy technologies for the UK. The south-west region in particular has the potential to generate substantial amounts of renewable energy from its wave and tidal stream resources. The South West of England Regional Development Agency (SWRDA) recognises the potential of the marine energy industry for the region and is supporting demonstration projects in marine energy through the Wave Hub project and the Peninsular Research Institute in Marine Renewable Energy (Primare). The Wave Hub project provides a unique opportunity for interdisciplinary research to aid developments in marine renewable energy. In this paper, a description of some of the new ongoing research being undertaken jointly by researchers at the Universities of Exeter and Plymouth within Primare is presented.

\section{INTRODUCTION}

Recognising the potential for marine renewable energy technologies in the south-west, the South West of England Regional Development Agency (SWRDA) is developing the Wave Hub project, ${ }^{1}$ which will provide a pre-commercialisation test site for arrays of wave energy devices, and the Peninsular Research Institute in Marine Renewable Energy (Primare), ${ }^{2}$ which is a collaboration between the University of Plymouth and the University of Exeter. The aim of Primare is to build up research capacity in marine renewable energy and to provide research support for Wave Hub and associated industries.

The Wave Hub concept is to provide an electrical grid connection to a point approximately $22 \mathrm{~km}$ off Hayle in Cornwall into which small arrays of wave energy devices would be connected. The aim is to speed up the commercialisation of wave energy converters (WEC; described elsewhere in this issue by Jones ${ }^{3}$ as marine energy convertors) by reducing the risk and cost for developers of the first pre-commercial wave machine arrays. Wave Hub will facilitate this by providing a well-defined and monitored site with electrical connection to the onshore electricity grid. The project received consent from the Department for Business, Enterprise and Regulatory Reform (BERR) and the Department for Environment, Food and Rural Affairs (Defra) in September 2007 and is scheduled to be commissioned in 2010. Four developers are preparing for deployment at the Wave Hub: Ocean Prospect/E.on ${ }^{4}$ are planning to install seven P750 Pelamis machines, each rated at $750 \mathrm{~kW}$; Ocean Power Technologies Inc. ${ }^{5}$ is planning a $5 \mathrm{MW}$ array of Powerbuoys; Fred Olsen Ltd $^{6}$ plan to deploy three of its Buldra WECs, in which buoys oscillate in heave under a floating platform; and finally, Oceanlinx ${ }^{7}$ plan to deploy its WEC, which is a large floating chamber that drives air through a turbine similar to an oscillating water column (Figure 1). (This list was correct at the time of writing; for the latest information please see the Wave Hub website. ${ }^{1}$ ) Each of the developers uses a different approach to extracting energy from the waves, although some of the engineering challenges are common to all.

The University of Plymouth and the University of Exeter are joint partners in Primare, which aims to address global renewable energy considerations as well as meeting the immediate needs of the emerging marine renewable energy sector in the south west, particularly associated with Wave Hub. The scope of the Wave Hub-Primare research spans inter-linked challenges, such as device optimisation and mooring systems, electrical systems, characterisation of the wave energy resource, environmental impacts on marine biodiversity, environmental impacts on the shoreline, beaches and wave climate, as well as collision avoidance and legal and socio-economic considerations. The research methodologies will encompass fieldwork through in situ and remote monitoring for baseline, midinstallation and long-term analysis of the impacts of an offshore wave farm, in addition to computational modelling and physical laboratory-scale modelling.

Primare's initial research strategy is to focus activity in support of the Wave Hub development in order to ensure that the 

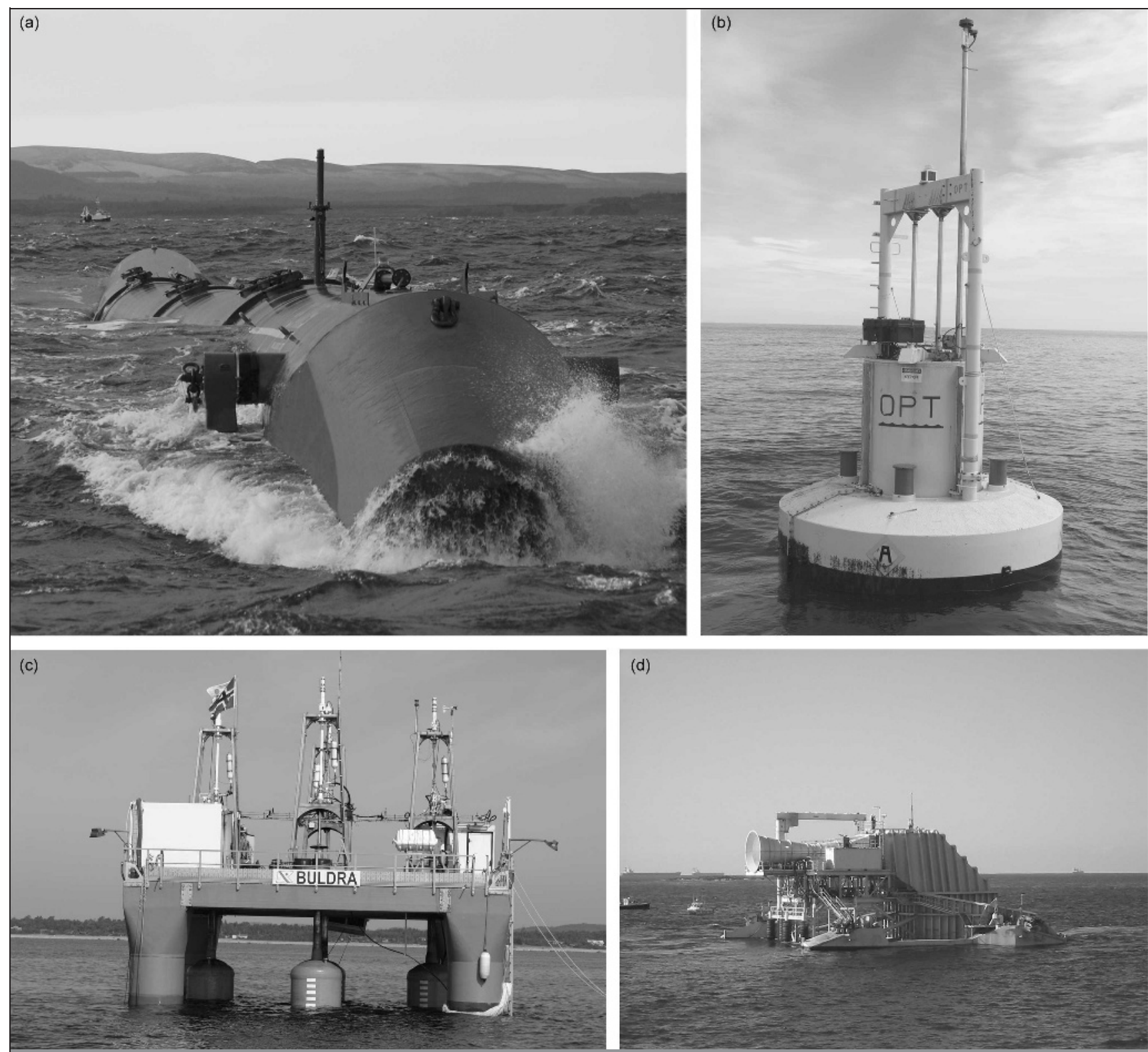

(d)

Figure I. Wave energy devices to be deployed at Wave Hub: (a) Pelamis; ${ }^{4}$ (b) Powerbuoy ${ }^{\circledR} ;{ }^{5}$ (c) Buldra; ${ }^{6}$ (d) Oceanlinx ${ }^{7}$

SWRDA, local, regional and national government and commercial stakeholders involved in Wave Hub can be furnished with appropriate research data to inform future decisionmaking. In this paper, aspects of Primare research associated with the Wave Hub project are described in the context of the key priority areas, illustrated in Figure 2. In Section 2, the research programme in marine operations is described; this encompasses the new WEC moorings field test facility and the development of numerical models for predictive analysis and design of WEC and mooring system and the use of control based upon deterministic wave prediction for improving survivability and performance of existing wave energy converters. In Section 3 , research into safe and economic operations and marine risk mitigation is described; underwater and surface electrical systems research is discussed in Section 4, and Section 5 introduces research to investigate legal regimes and socioeconomic factors affecting Wave Hub. In Section 6, research studying the environmental impact of Wave Hub is discussed. This includes both the impacts on the physical environment; seabed, shoreline and water column, and the impacts on the marine biodiversity at a range of scales; benthic, fish, birds and

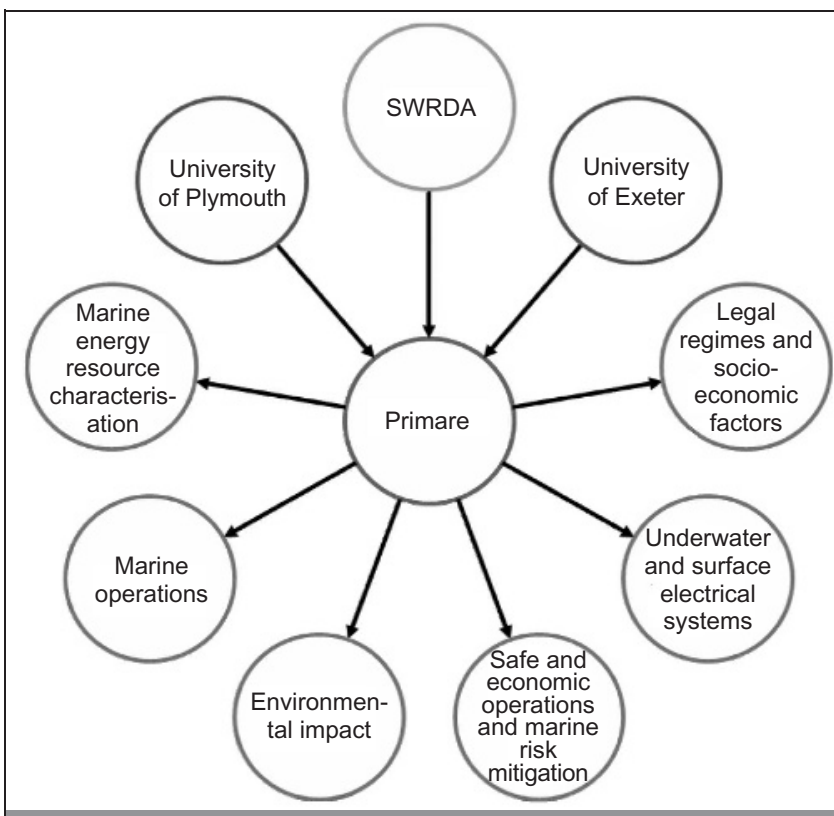

Figure 2. Primare research priority areas 
cetaceans. Marine energy resource characterisation through wave measurement and numerical wave prediction is described in Section 7, and conclusions are given in Section 8.

\section{MARINE OPERATIONS}

\section{I. Device optimisation and moorings}

Although recognised as a realistic contender in achieving the UK government targets for renewable energy, offshore wave energy conversion remains a very expensive option compared with conventional methods for electricity generation and even other renewable sources. ${ }^{8}$ This is partly due to the high cost of operations offshore, the need to operate in a high-energy wave climate and to survive extreme storm events. The survivability of devices in storm conditions is particularly challenging. The device may be de-tuned or decoupled to protect the power takeoff system, but nevertheless the mooring system must hold the structure in place in all weather conditions including extreme storms.

Traditional design methods for wave loading on offshore structures are unable to predict the violent events of breaking, overtopping and slamming impacts on bodies that may have dynamic responses around the wave frequency. In order to predict violent surface motions and wave-structure interaction, a fully non-linear approach is necessary, in which both the water and air that may be entrained when a wave breaks or overtops a structure are modelled, and the interface between them defined with high-resolution free surface capturing techniques. Computer simulations developed here incorporate local grid refinement and grid adaptation together with parallel programming to speed up the solution, and make use of Primare high-performance computing facilities. Figure 3 shows a numerical example incorporating high-resolution free surface

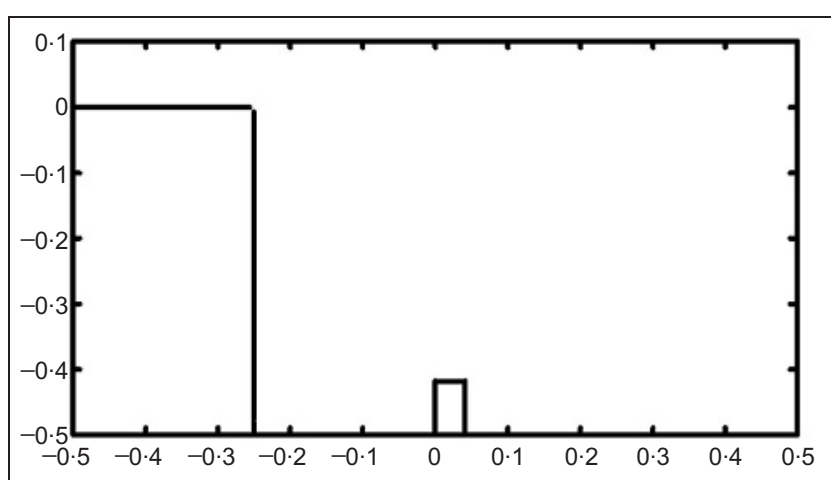

(a)

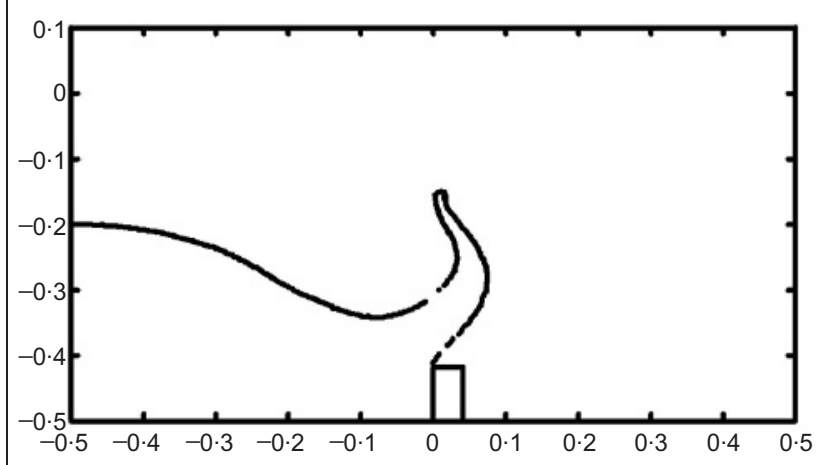

(c)

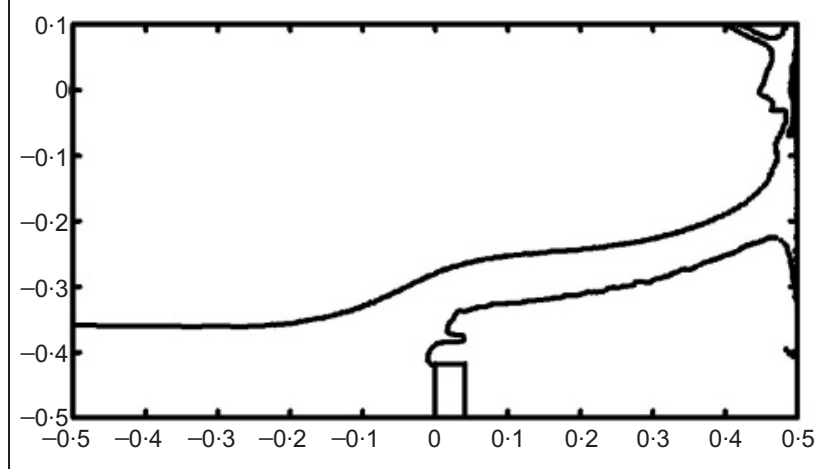

(e)

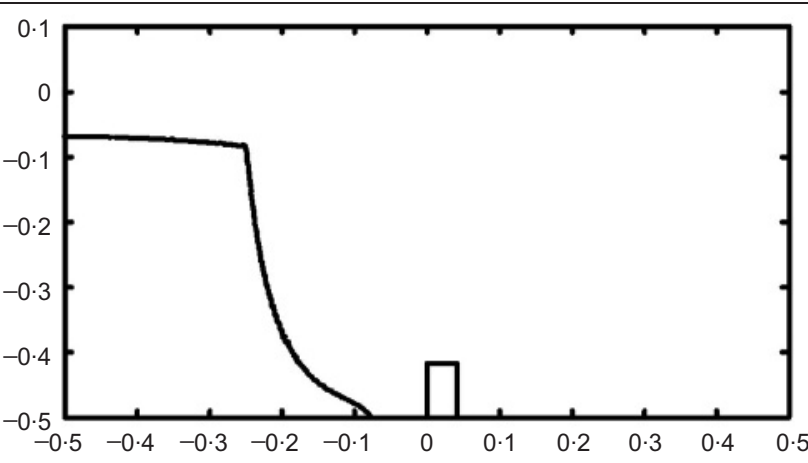

(b)

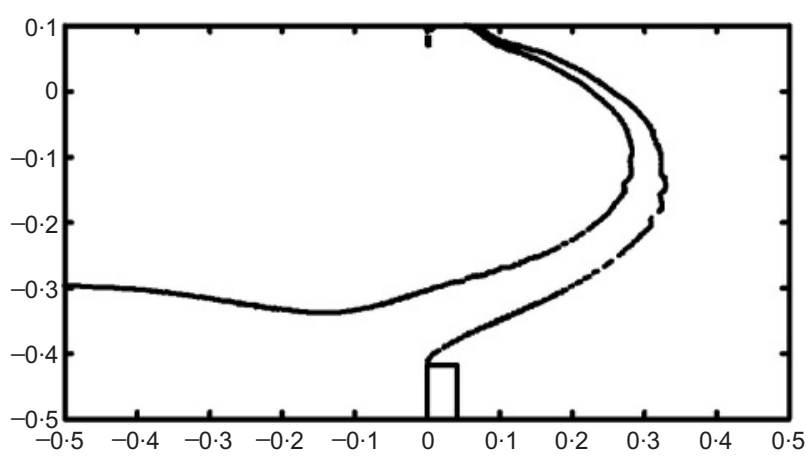

(d)

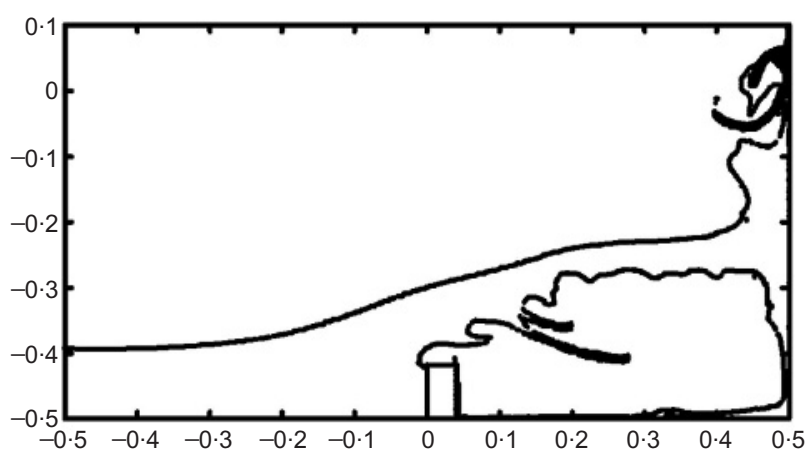

(f) 
capturing in a two-fluid flow simulation. Snapshots in time of the free surface calculated for simulation of dam collapse and interaction with an obstacle are presented. The column of water is initially held stationary by a vertical wall, which is removed instantaneously, causing the water column to collapse. A jet runs along the base of the tank, hits the obstacle and shoots up into the air. After hitting the right-hand wall, the jet collapses back down the wall to the base of the tank entrapping a large bubble of air. These snapshots are qualitatively similar to photographs taken of the experiment by Koshizuka et al. ${ }^{10}$ and published by Greaves. ${ }^{9}$

Furthermore, the dynamic response of WECs in waves is significantly different from traditional offshore structures. This is mainly due to the fact that WEC structures have typically small length scales relative to the wave length, whereas offshore oil and gas structures are relatively large in comparison with the wavelength. As a result, the top-end responses due to hydrodynamic loadings and their influence on the coupled system of top-end structure and mooring system will be different for WECs from those for offshore oil and gas installations. In the case of a coupled moored system with non-linear mooring response, the behaviour of the mooring system itself can actively contribute to the dynamic motion characteristics of the top-end structure, contributing to peak loadings and large accelerations. The importance of the mooring contribution to a coupled moored WEC device is discussed, for example, by Johanning and Smith, ${ }^{11,12}$ and Johanning et al. ${ }^{13}$ who indicate the importance of peak line tensions associated with mooring line stiffness and damping (Figures 4 and 5). These factors suggest that a new approach must be taken to understand combined wave, current and wind loading on floating WECs.

Primare research investigating the survivability of WECs and their mooring systems in extreme conditions as well as and under normal production conditions encompasses numerical modelling, wave tank experiments and field tests. Numerical modelling for design of mooring systems and laboratory-scale experiments to verify design loadings under controlled conditions are essential components of the mooring design process. Sophisticated numerical models are being developed to simulate the non-linear coupled dynamic response of a WEC and mooring system under the combined effects of waves, current and wind. ${ }^{14}$ These models will incorporate the high-resolution free surface capturing and two-fluid flow simulation as mentioned above. The wave inlet boundary condition will be informed by the numerical wave prediction for resource characterisation, described in Section 7 and the field measurements described in Sections 6 and 7.

Field-scale experiments are difficult to achieve, but improve understanding of the mooring system behaviour in real sea conditions and give confidence in the numerical models and laboratory-scale tests. A field site for testing moorings at half scale (referenced to the wave climate at the Wave Hub) is being established by Primare in order to assess and evaluate different mooring systems. A buoy and mooring system will be fully instrumented to record the environmental climate (waves, wind, current), buoy response and loading on the mooring lines. ${ }^{15}$ This facility is internationally unique and will provide accurate information on mooring line response under realistic conditions of wave, current and wind.

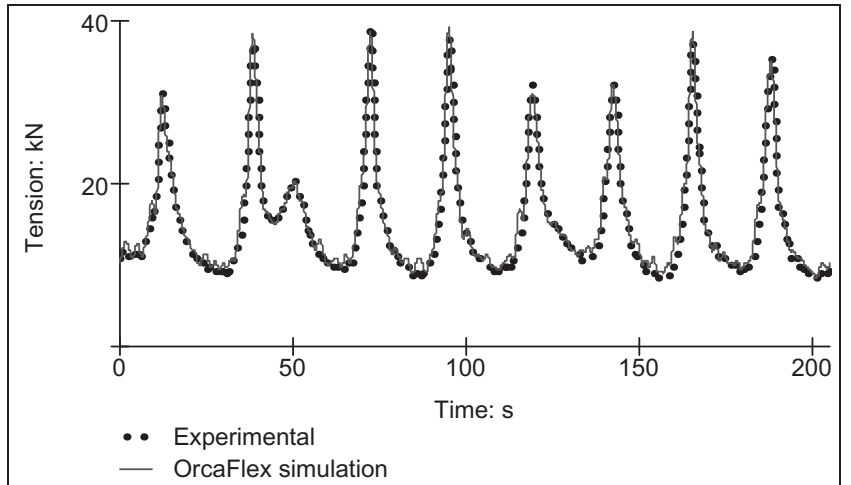

(a)

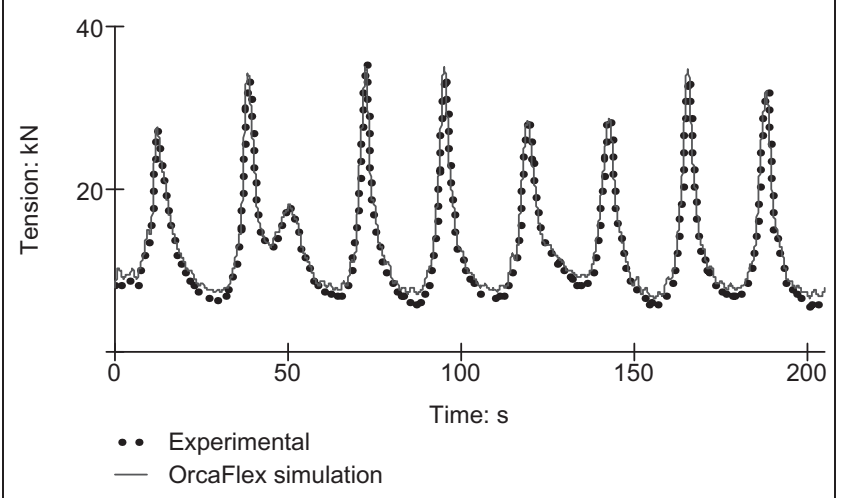

(b)

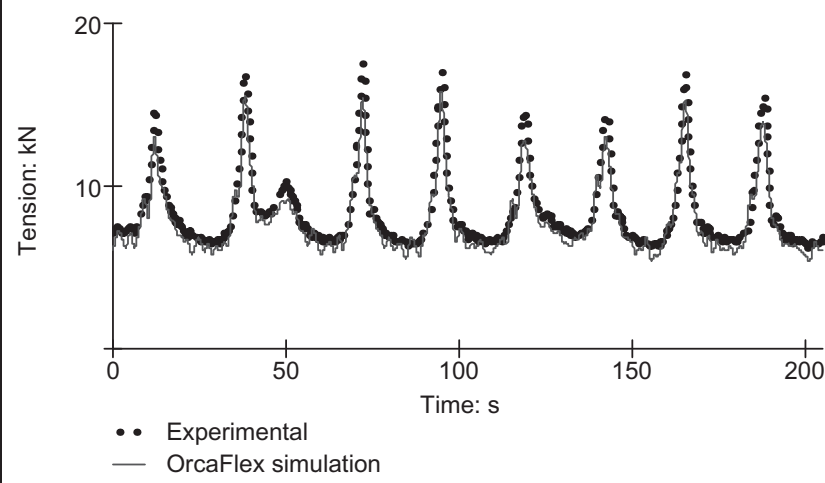

(c)

Figure 4. Measured and predicted (a) axial, (b)horizontal and (c) vertical peak line tensions ${ }^{\prime \prime}$

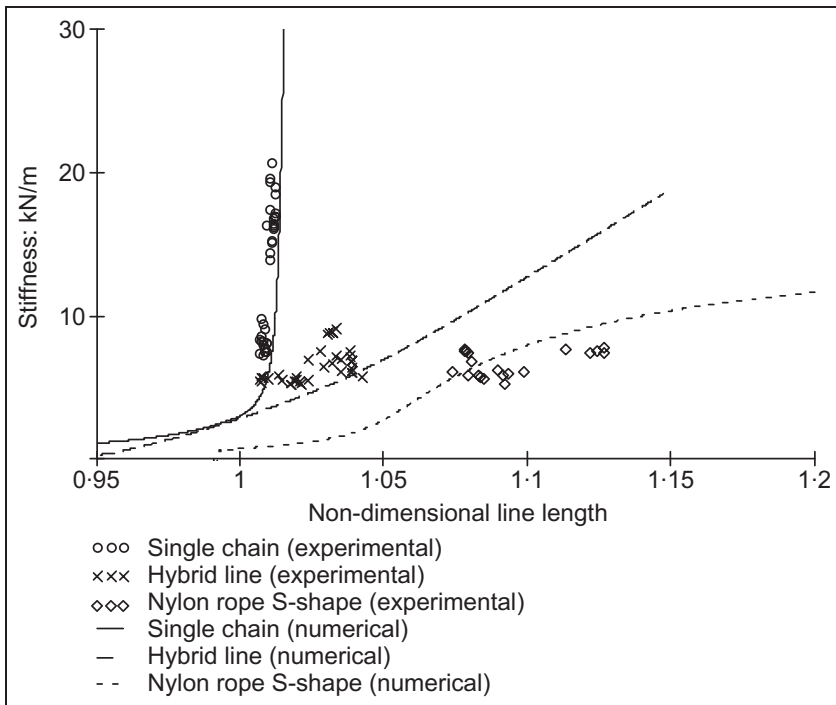

Figure 5. Measured and predicted stiffness characteristics for a catenary chain, hybrid line and nylon rope S-shape 
These different research strands will be fully integrated by crosscomparison of the numerical, wave tank and field test data and findings will be compared with traditional design methods for moorings in order to draw out recommendations and guidelines for WEC mooring system design.

\subsection{Marine operations control}

In the development of a new technology such as wave energy conversion there is inevitably a tension between $(a)$ getting existing systems operational in the field to generate revenue so as to exploit investment already made, and (b) improving upon present systems so as to ensure the best possible technology is actually employed. In the case of many WEC devices, a third factor is present, namely operating existing WECs in the most effective manner.

One aspect of WEC operation that falls under this heading is tuning of the device, in which the dynamic characteristics of the WEC are matched to the prevailing sea conditions. This subject has been extensively explored by Falnes ${ }^{16}$ and most WEC developers have some involvement in the area. However, with very limited exceptions the focus is upon either tuning to the short-term average (20 min typically) power spectrum of the prevailing sea conditions or using very local wave data at the WEC for dynamic adjustment. This misses the benefits available from so-called wave-by-wave tuning, which recognises that each incoming wave set differs significantly from the prevailing short mean spectrum. To realise this type of tuning it is necessary to predict the detailed shape of the sea that will arrive at the WEC up to $20 \mathrm{~s}$ ahead in time. This involves the new subject of deterministic sea wave prediction. ${ }^{17-19}$

An even larger potential for operational improvement is the socalled quiescent period prediction. This arises because WECs can only safely absorb power from waves up to some limiting wave properties (mainly slope and amplitude). Beyond the limiting wave properties they must be uncoupled. This suggests using standard 20 min sea power spectra to control shutdown. Unfortunately if there is any chance that wave limits will be exceeded in the averaging period, operation is prohibited during the whole interval, which may lead to shutdown of unnecessary length. An alternative is to 'over engineer' devices to the point where they become totally uneconomic. However, as with tuning, if deterministically predicted short-term wave shape estimates are used to control shutdown on a wave-by-wave basis it is possible to obtain improvements in mean WEC output safely by many tens of per cent. ${ }^{20-23}$ The basis for quiescent period control is indicated schematically in Figure 6.

\section{SAFE AND ECONOMIC OPERATIONS AND MARINE RISK MITIGATION}

Possible danger to shipping is an important consideration for planning of offshore renewable energy installations. Due to the near invisibility of some WEC designs to mariners, there is concern over the potential marine hazard introduced by wave farms. Work is being undertaken to examine the risks to safe surface navigation in the vicinity of the marine renewable energy device arrays. This includes the development of navigation scenarios to investigate the risks identified and the effectiveness of existing mitigation methodologies under development. Further evaluation will be undertaken through simulation and prototyping of novel methods for mitigating the risks identified. As part of this, ship-to-structure collision risks and their mitigation and the factors affecting safe navigation in the vicinity where wave energy devices are deployed are under investigation.

\section{UNDERWATER AND SURFACE ELECTRICAL SYSTEMS}

Quite apart from the difficult issue of energy conversion and power take-off system for an individual device, when installed as an array, the complexity of underwater electrical connections and compatability of generation from different WECs needs to be considered. At the Wave Hub an under water interconnector is connected through transformers to arrays of four different WEC devices (Figure 7). Research is under way to understand and investigate problems that may occur arising from the different electrical characteristics of each device and also to take into account the possibly intermittent nature of the power produced from each berth. Problems might occur in transient and dynamic stability and power quality, and these effects would feed through onto the power generated and delivered into the grid. In this research, new techniques for control are investigated that can overcome problems arising from faults within devices and sudden changes to their properties. These techniques can also help mitigate against the effect of

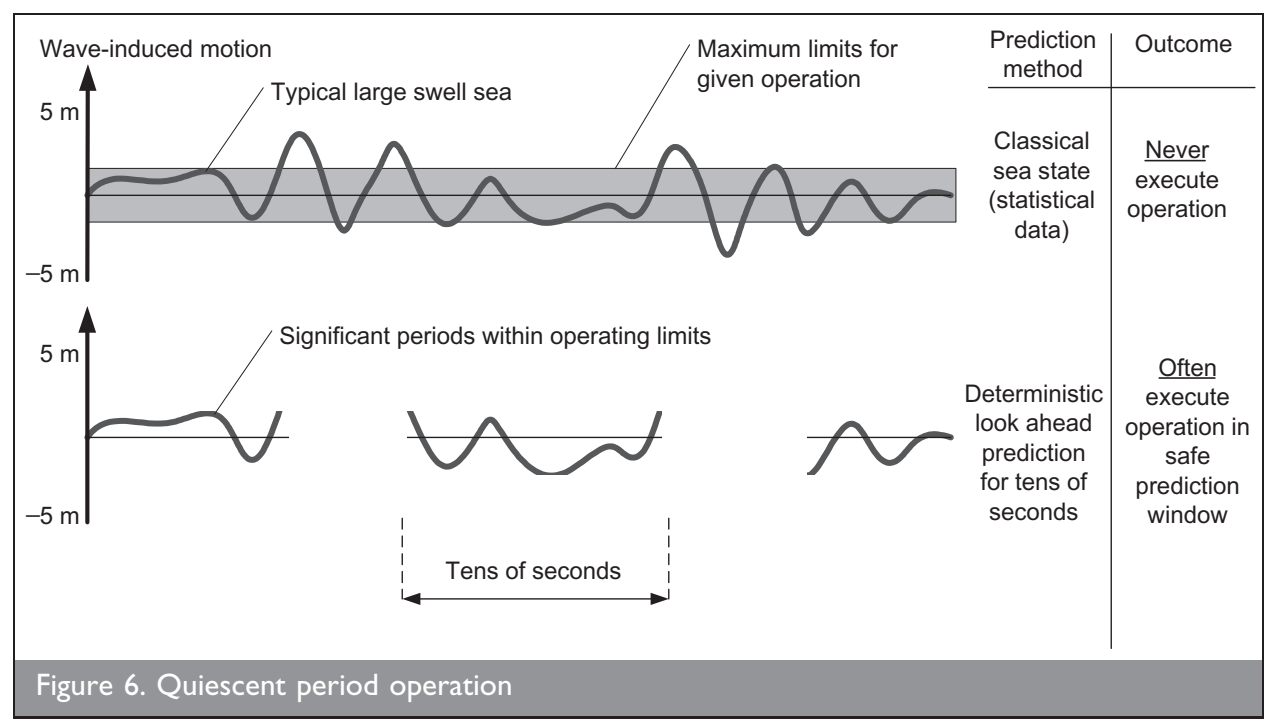




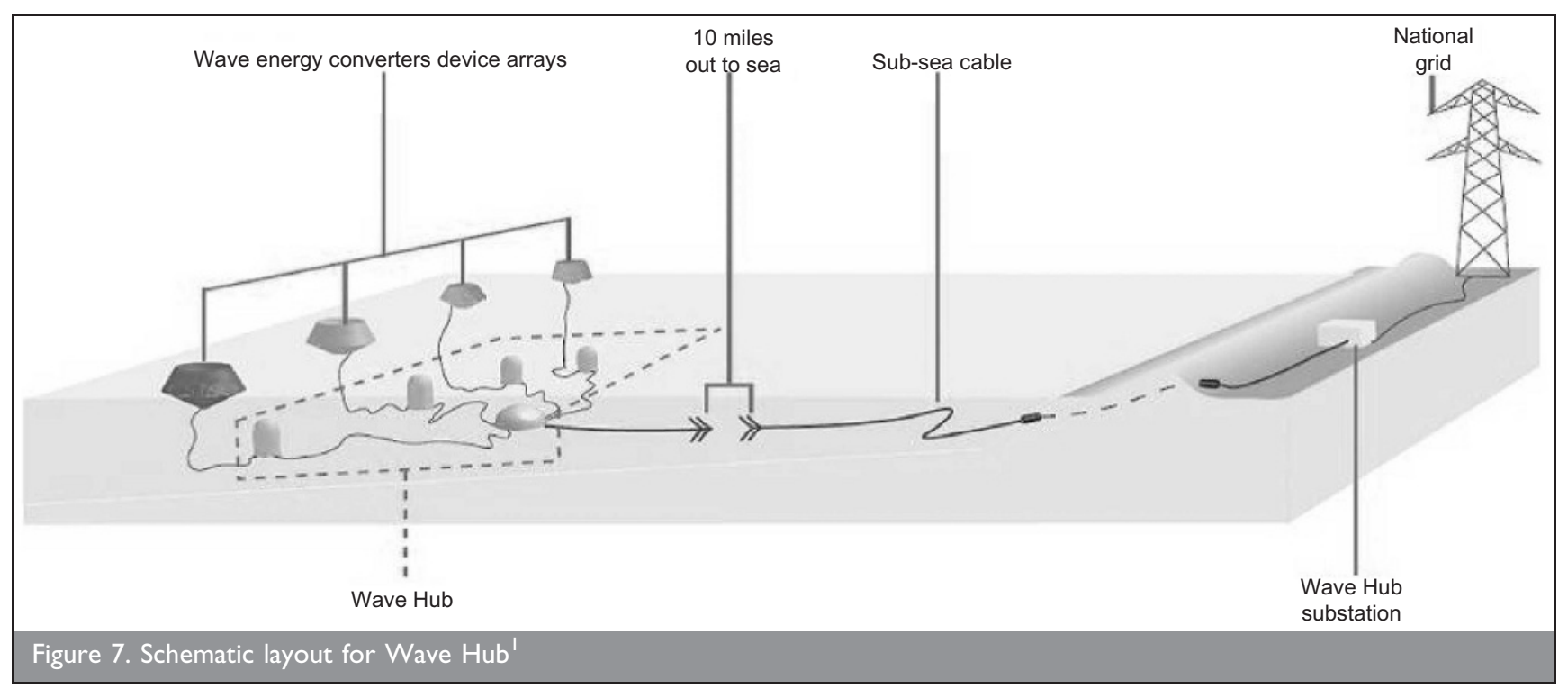

intermittent wave power from the different devices.

A new laboratory research facility for simulation and demonstration of complex electrical systems is being established by Primare. This allows research into the behaviour of power systems and integration of marine renewable energy into the grid under a variety of operational scenarios. The facility comprises a real-time grid interconnection and system integration-testing platform for the Wave Hub project. The dynamics of marine power systems is being evaluated and data gathered on long-term performance in order to demonstrate innovative design concepts. The facility provides advanced equipment and test beds to characterise the performance and reliability of marine power systems, and research into wide area protection. This research will be important in enabling different scenarios and performance combinations to be tested and in developing mitigation measures for this new technology in the safety of the laboratory. In the longer term, it is hoped that the research will help to facilitate greater penetration of distributed generation from arrays of marine energy converters into the grid network.

\section{LEGAL REGIMES AND SOCIO-ECONOMIC FACTORS}

The creation and operation of the Wave Hub as a demonstration project offers an unprecedented opportunity for investigation of the implications of marine renewable energy to the socioeconomic systems of the UK in general and those around the south-west region in particular. The introduction of the Wave Hub aims to produce benefits at the national and local levels in terms of environmental protection, security of energy supply, as well as job creation and infrastructure renewal, and so on. However, these positive impacts must be weighed against possible negative impacts of the project in terms of socioeconomic and environmental impact on land and at sea and the potential limitations these place on the establishment and development of large-scale marine renewable energy projects.

A large infrastructural development such as the Wave Hub presents a number of challenges on the existing economic, social, natural and cultural heritage of host areas. Conflicts are likely to emerge in the marine environment between different activities, users and purposes governed by a patchwork of common and private property rights, as well as customary and statutory rules and regulations. Essential sea uses other than energy generation must be accommodated within the concept of integrated coastal management. Furthermore, maritime traffic in the vicinity of the Wave Hub must be recognised as an issue of significant concern. Safety, security and environmental protection measures must be designed pursuant to policy development taking account of legal and socio-economic perspectives.

To address these issues, Primare research is being developed in four interrelated areas to ensure a holistic assessment of the Wave Hub. These are: the legal regimes, socio-economic sustainability, cost-benefit analysis and planning. This research is carried out by a multidisciplinary group involving economists, legal scholars and lawyers, geographers, social scientists and environmental scientists. Research in the legal area is under way to identify and critically examine the legal regimes governing UK coastal waters and to investigate their implications for maritime safety and security and marine environmental protection in the context of the establishment and operation of wave energy generation devices. Analysis of the socio-economic implications of the Wave Hub project is based around the broad concept of socio-economic sustainability and, more specifically, sensitivity analysis of key assumptions underpinning the benefits projected to arise from the project. A cost-benefit analysis framework is adopted to measure and compare all values lost with all values gained as a result of the project. Attempts will also be made to develop a methodology for implementation of marine spatial planning for marine and coastal activities including marine renewable energy generation.

\section{ENVIRONMENTAL IMPACT}

\section{I. Biodiversity impacts}

The environmental impact assessment is an essential feature of the planning process necessary for marine renewable energy installations. Benefitting from its involvement with the Wave Hub project at an early stage, Primare has a unique opportunity to perform thorough monitoring of marine biodiversity at the site, before, during and after installation. The aim of this work is to gain a detailed understanding of key components of the marine ecosystem at the wave energy test site and to assess its 
impact on these components; these impacts may be potentially either positive or negative. Defining the baseline over a period of at least 1 year prior to construction is a vital aspect of this work and combined with regular longer-term monitoring and observation, this will allow the immediate effects during the construction and deployment phase to be investigated as well as the subsequent impact once the Wave Hub is up and running. Commercial wave farms will need to operate within a 'marine safety zone', which will function as a de facto marine protected area (MPA), so part of this work will investigate whether this exclusion of other activity, such as fishing, acts as an MPA in providing refuge for commercial fishery species and increases marine biodiversity on the sea bed.

Marine renewable energy installations are likely to have impacts at both local and wider ecosystem scales. These differing scales will be investigated through targeting three main areas: the impact on the benthic biodiversity of the enclosed area; an appraisal of the population distribution and movement (through dispersal) of some of the fish associated with the Wave Hub; and the impact on higher vertebrates, such as seabirds and, particularly, the impact of noise on marine mammals. State-of-the-art technology will be used to quantify all aspects, including high-definition video sampling of the sea bed using remotely operated vehicles (ROVs), acoustic monitoring of cetacean sound and satellite tracking of larger organisms, particularly birds. This is supported by classic methodology, such as quantitative potting and tagging of crabs and lobsters. Additional research on the population structure, distribution and movements of marine fish associated with the Wave Hub will be achieved through acoustic tagging of several species of roundfish, flatfish and elasmobranchs.

Monitoring of marine biodiversity will assist in assessing the direct effects of the wave farm construction and WECs; and analysis of the indirect effects resulting from the instigation of any safety zone or MPA will be used to advise on how to maximise the benefits of future offshore renewable energy installations. The breadth of the biodiversity impacts research will allow assessment of the impact of offshore renewable energy schemes on all aspects of the ecosystem and thus build a picture of effects on species of high fisheries and conservation value that are of concern to many stakeholders, such as the fishing industry and the wider public.

\subsection{Wave hub impacts on seabed, water column and shoreline processes}

Numerical modelling and wave measurement work for resource characterisation, which is described in Section 7, is being carried out alongside a comprehensive programme of field measurement in the coastal area surrounding the Wave Hub site. The aim of this field work is to measure and assess any significant wave attenuation attributable to Wave Hub, to monitor changes in sedimentation in the lee of Wave Hub from the installation to the beaches and to monitor changes in coastal bathymetry, beach topography and beach state at key sites throughout the Wave Hub commissioning and operational phases. This field study will help to quantify the impact of Wave Hub, if any, on surfing and general recreational use of the beaches. Further measurements will be taken in the lee of the Wave Hub to identify and quantify the impact of energy extraction on the water column structure.
The Wave Hub site is close to popular extensive sand beaches on the north Cornwall coastline which are well-known for surfing and other marine recreational activities and central to Cornwall's tourism industry. In order to investigate potential impacts of the Wave Hub development on the shoreline, an extensive study of the nearshore region is under way. This involves the development of a historic database of shoreline positions and shallow water bathymetry for beaches which represent locations shadowed by the Wave Hub as well as those free of shadow. This database is then to be complemented by active monitoring of subaerial bathymetry, using photographic monitoring (Figure 8) and incident waves and currents, using a mobile acoustic Doppler current profiler (ADCP) unit, for a continuous period spanning more than 2 years prior to and following the wave farm installation. Numerical models of nearshore morphology shall be employed in these areas to complement the measurements. Informed by results of the work performed here, a suggested methodology for future monitoring of other marine renewable energy projects will be developed.

The impacts of Wave Hub between the sea surface and seabed will be monitored by measuring turbulence intensity throughout the water column. Turbulence is a fundamentally important property within the ocean as it acts to homogenise water parcels with different densities. It will be measured within the vicinity of the Wave Hub by a vertical microstructure profiler, shown in Figure 9, which measures turbulent velocity fluctuations at millimetre-scales. Continuous hydrographic surveys performed with undulating towed sensors which measure water properties such as temperature and salinity will complement the turbulence measurements.

Extraction of energy from the surface waves is likely to reduce the amount of turbulence near the sea surface and lead to a greater degree of vertical stratification. This has implications not only for the physical environment, in which different hydrodynamic processes are supported by a stratified water column compared to a well-mixed environment, but also for the biological community. Stratification inhibits the vertical transport of nutrients to the photic zone, where increased light availability stimulates primary production. During spring, this may stimulate the annual bloom of phytoplankton, but at other

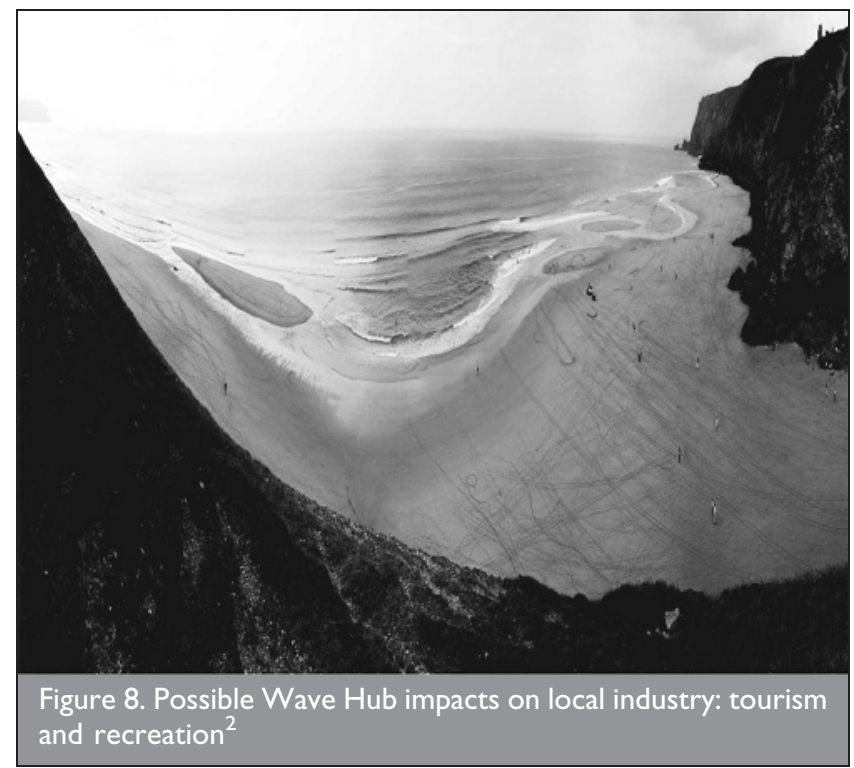




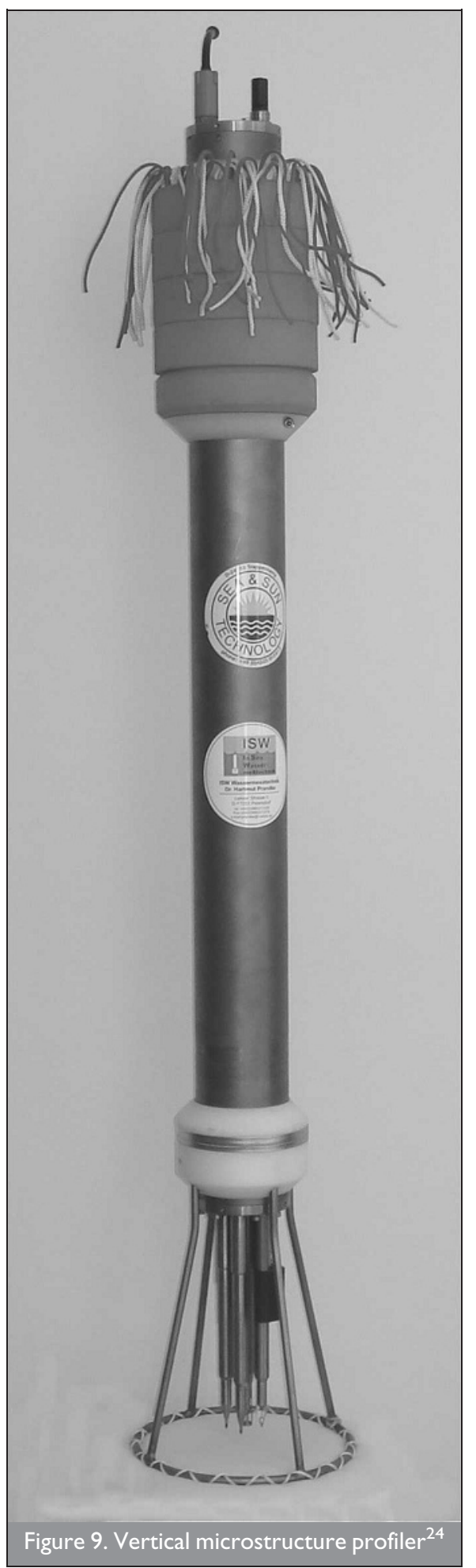

times may deny the surface layers of the essential nutrients required to maintain growth. Furthermore, many species of fish and larvae are known to actively avoid turbulence. Thus, in better understanding how the Wave Hub impacts on the location and intensity of turbulence, this research will have interdisciplinary implications and close links with studies of the impact of Wave Hub on biodiversity, where it will be fundamental to understanding the response of the biological community.

\section{MARINE ENERGY}

\section{RESOURCE CHARACTERISATION}

Primare research in this area involves the deployment of an array of wave measuring devices at, or near, the Wave Hub site, together with extensive wave modelling. The classical method for wave monitoring is through the deployment of wave buoys or, more recently, bottom-mounted ADCP sensors which provide single point measurements of the ocean directional wave spectra (Figure 10). A time-correlated array of buoys is to be deployed around the site and will provide extensive understanding of the effect that spatial variations can have on energy production.

Pictured in Figure 10(a) is a directional wave measurement buoy employed by D. Vandemark and colleagues at the University of New Hampshire for wave monitoring in the Gulf of Maine. The waverider buoy is built by Datawell BV and is part of a US network of these moorings supported by the CDIP program at Scripps Institute of Oceanography.

Recent advances in high-frequency (HF) radar measurement techniques ${ }^{25}$ permit the collection of the type of spatial information which would enable the temporal and spatial distribution of waves surrounding the installation to be investigated. However, validation studies of these measurements have always been based on the use of single point control measurements, which are typically collected in the centre of the measurement field. As a result, little is known about the spatial reliability or relative errors of the HF radar wave measurements. Primare plans a unique study of the integration of HF radar measurement in combination with the wave measurement array. With the deployment of a large number of single point measuring devices at Wave Hub, Primare has the opportunity to examine the spatial characteristics of these measurements and to validate a convenient wave monitoring technique for future wave farm installations, which can complement and extend the single point measurement data.

Measurement of the wave climate through wave buoys, ADCPs and HF radar will be further complemented by numerical modelling. The aim is to improve current numerical models, through comparison with measurements, and to develop models to provide a predictive capacity for the site. Nested wave models will be used to improve site-specific wave climate assessment, to investigate wave farm effects on the wave climate and to investigate the downstream impacts of the wave farm on adjacent beaches. ${ }^{26}$ The numerical wave modelling will provide a characterisation of the wave climate in terms of the probabilities of occurrence of different wave height, period and direction combinations. ${ }^{27-29}$ The models will also allow prediction of the wave climate and coastal impacts of a wave farm under various climate change scenarios.

\section{CONCLUSIONS}

The Wave Hub project will establish the world's first large-scale wave energy test site, at which device arrays utilising four different designs will be connected. Wave Hub will provide a test bed for impacts and planning issues particularly related to wave farm development and is ideally situated for this purpose on the north Cornish coast, which has as wide a range of stakeholders as any other potential marine energy location. Through its association with Wave Hub, Primare has the unique benefit of relevant stakeholder involvement at all stages of the research including early scoping, thus ensuring its relevance and value to beneficiaries. Primare will take advantage of the potential for applied and pure research offered by Wave Hub. These will range from technology-specific research to more broad-based environmental and socio-economic aspects that must be 


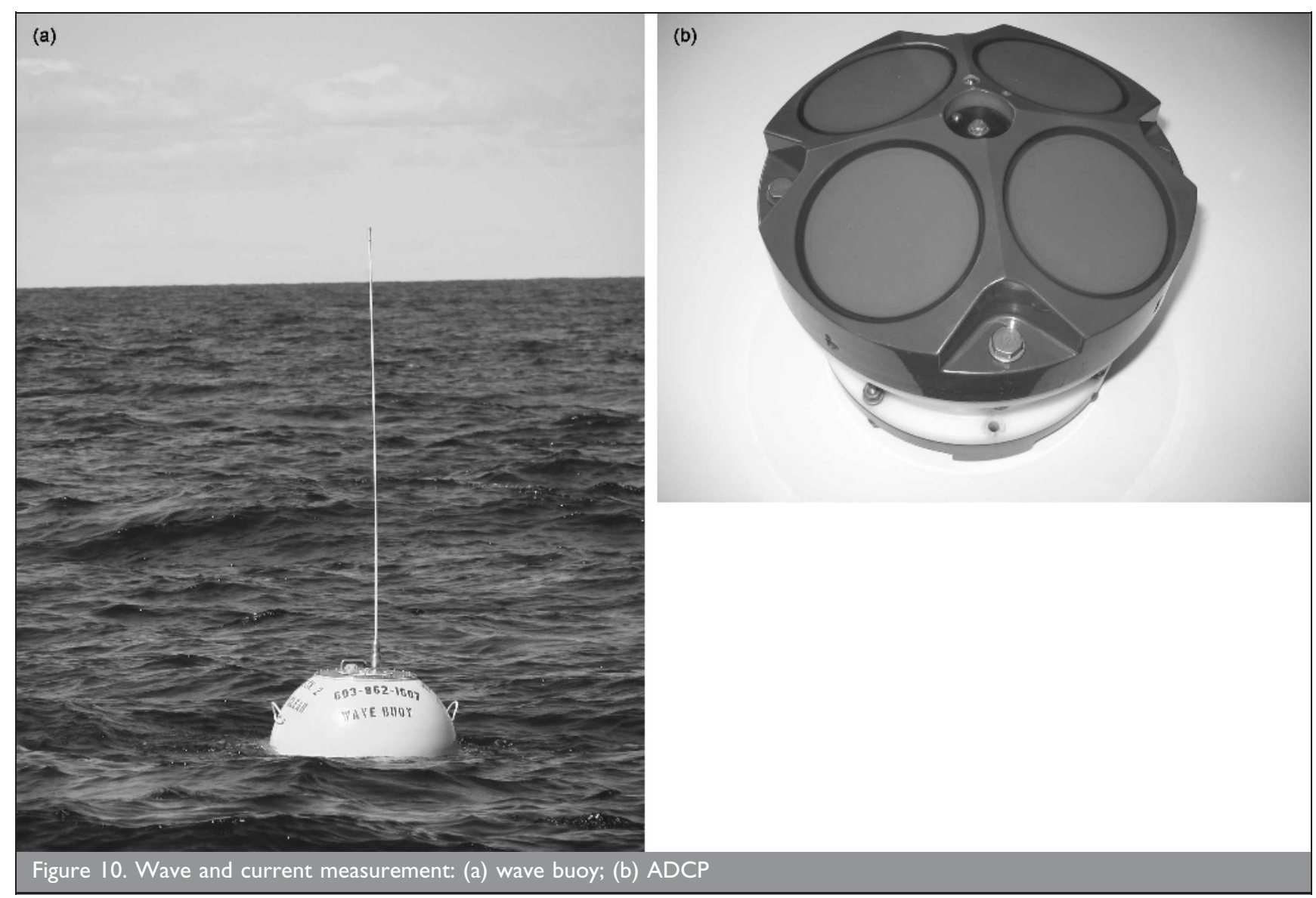

addressed. A full range of impact studies will be undertaken including base line surveys which are comprehensive both in time and spatial extent. These pioneering studies will without doubt form exemplars for other developments to follow. The Wave Hub and associated research backed by stakeholder engagement will be an excellent demonstration project for the marine renewable sector and it is hoped that the knowledge gained will help to accelerate commercialisation of future wave farms.

\section{ACKNOWLEDGEMENTS}

The authors are grateful to the South West Regional Development Agency and the European Commission for supporting this work through the Peninsular Research Institute for Marine Renewable Energy (Primare).

\section{REFERENCES}

1. See http://www.wavehub.co.uk. Accessed 23/10/2009.

2. See http://www.primare.org. Accessed 23/10/2009.

3. JoNES A. Demonstrating survivability of marine energy convertors. Proceedings of the Institution of Civil Engineers Maritime Engineering, 2009, 162, No. 4, 179-185.

4. See http://www.pelamiswave.com. Accessed 23/10/2009.

5. See http://www.oceanpowertechnologies.com/index.htm. Accessed 23/10/2009.

6. See http://www.fredolsen-renewables.com/. Accessed 23/10/ 2009.

7. See http://www.oceanlinx.com. Accessed 23/10/2009.

8. PARSONS BrinKerhof. Summary Report. Powering the Nation a Review of the Costs of Generating Electricity. Parsons Brinkerhof, Newcastle Upon Tyne, 2006. See http://www. pbworld.co.uk/index.php?doc $=528$. Accessed 23/10/2009.
9. Greaves D. M. Simulation of viscous water column collapse using adapting hierarchical grids. International Journal for Numerical Methods in Fluids, 2005, 50, No. 6, 693-711.

10. KoshizUKa S., Tамако H. and OKa Y. A particle method for incompressible viscous flow with fluid fragmentation. Computational Fluid Mechanics Journal, 1995, 4, No. 1, $29-46$.

11. Johanning L. and SMith G. H. Improved measurement technologies for floating WEC mooring arrangements. International Journal of the Society for Underwater Technology, Special Issue (OISI), 2008, 27, No. 4, 175-184.

12. JohAnNing L. and SMith G. H. Station keeping study for WEC devices including compliant chain, compliant hybrid and taut arrangements. Proceedings of the 27th International Conference on Offshore Mechanics and Arctic Engineering (OMAE), 15-20 June 2008, Estoril, Portugal. ASME, New York, NY, USA, 2008, No. OMAE2006-57184.

13. Johanning L., Smith G. H. and Wolfram J. Measurements of static and dynamic mooring line damping and their importance for floating WEC devices. In: Ocean Engineering 1918-1934. Elsevier, Amsterdam, The Netherlands, 2007, Volume 34.

14. Zhang Y., Zou Q. and Greaves D. M. Numerical simulation of two phase flow using the level set method with global mass correction. International Journal for Numerical Methods in Fluids, 2008, submitted.

15. Johanning L., Spargo A. W. and Parish D. Large scale mooring test facility: a technical note. Proceedings of the 2nd International Conference on Ocean Energy 2008 (ICOE 2008), Brest, France, 15-17 October 2008.

16. Falnes J. Ocean Waves and Oscillating Systems. Cambridge University Press, Cambridge, 2002. 
17. Morris E. L., Zienkiewicz H. K., PurZanjani M. M. A., Flower J. O. and Belmont M. R. Techniques for sea state prediction. Proceedings of the 2nd International Conference on Maneuvering and Control of Marine Craft, Southampton. Elsevier, Amsterdam, The Netherlands, 1992, pp. 547-571. 18. Purzanjani M. M. A., Belmont M. R., Zienkiewicz H. K. and MorRIS E. L. Applications of a sea-surface estimator in predictive ship control. Proceedings of the 2 nd International Conference on Maneuvering and Control of Marine Craft, Southampton. Elsevier, Amsterdam, The Netherlands, 1992, pp. 581-591.

19. Morris E. L., ZienKiewicz H. K. and Belmont M. R. Short term forecasting of the sea surface shape. International Journal of Shipbuilding Progress, 1998, 45, No. 444, 381-400.

20. Falnes J. Ocean Waves and Oscillating Systems. Cambridge University Press, Cambridge, 2002.

21. KoRde U. A. Control system applications in wave energy conversion. Proceedings of the Oceans Conference 2000. IEEE, Los Alamitos, CA, USA, 2000, Proc.3, pp. 1817-824.

22. EIDSMOEN H. On Theory and Simulation of Heaving Buoy Wave Energy Converters with Control. PhD. thesis, Norwegian University of Science and Technology, Trondheim, Norway, 1996.

23. SAlter S. H. Changing the 1981 spline-based ducks.
Proceedings of the 1st European Wave Energy Conference, Edinburgh, 1993.

24. See http://www.isw-wasser.com/. Accessed 23/10/2009.

25. Wyatt L. R., Thompson S. P. and Burton R. R. Evaluation of high frequency radar wave measurement. Coastal Engineering, 1999, 37, No. 3-4, 259-282.

26. Millar D., Smith H. C. M. and Reeve D. E. Modelling studies of the sensitivity of the shoreline wave climate to the proposed wave farm development off the north coast of Cornwall. Ocean Engineering, 2007, 34, No. 5-6, 884-901.

27. Smith G. H., Venugopal V. and Wolfram J. Wave period group statistics for real sea waves and wave energy extraction. Proceedings of the IMechE Part M: Journal of Engineering for the Maritime Environment (special edition for Marine Renewable Energy), 2006, 220, No. 3, 99-115.

28. Smith G. H. and Venugopal V. A generic method for determining WEC power conversion from a random sea. Proceedings of the 16th International Offshore and Polar Engineering Conference (ISOPE), San Francisco, 2006.

29. Smith G. H., Venugopal V. and Fasham J. Wave spectral bandwidth as a measure of available wave power.

Proceedings of the 25th International Conference on Offshore Mechanics and Arctic Engineering (OMAE), Hamburg, June 4-9 2006. OMAE2006-92379.

\section{What do you think?}

To discuss this paper, please email up to 500 words to the editor at journals@ice.org.uk. Your contribution will be forwarded to the author(s) for a reply and, if considered appropriate by the editorial panel, will be published as discussion in a future issue of the journal.

Proceedings journals rely entirely on contributions sent in by civil engineering professionals, academics and students. Papers should be 2000-5000 words long (briefing papers should be 1000-2000 words long), with adequate illustrations and references. You can submit your paper online via www.icevirtuallibrary.com/content/journals, where you will also find detailed author guidelines. 